\title{
Celiac Disease in Association with a Congenital Heart Disease
}

\author{
Maniram Kumhar, Chetan Kumar A*, Deepa Kulkarni \\ Department of General Medicine, Jawaharlal Nehru Medical College, Ajmer, Rajasthan, India \\ *Corresponding author: drck.medicine@gmail.com
}

Received October 21, 2013; Revised November 12, 2013; Accepted December 13, 2013

\begin{abstract}
Celiac disease is a form of enteropathy affecting the (small) intestine in genetically predisposed children and adults, precipitated by the ingestion of gluten-containing foods. It is also referred to as celiac sprue, glutensensitive enteropathy, and nontropical sprue. Though its presentation is commonly associated with the gastrointestinal system other systemic associations like hepatobiliary system, nervous system, hematologic system, cardiovascular system are not uncommon. We hereby present a case of a 14 year old girl with a history of global growth retardation. Systemic examination suggested severe anemia, massive pleural and pericardial effusions subsequently confirmed by chest $\mathrm{x}$ ray and echocardiography which also revealed an underlying atrial septal defect. Raised levels of serum anti-transglutaminase antibody (IgA) arose suspicion of Celiac disease which was confirmed after the histopathological study of the duodenal biopsy. We are reporting this case to highlight a rare association of celiac disease with a congenital heart disease.
\end{abstract}

Keywords: celiac, growth retardation, atrial septal defec, tissular anti-transglutaminase antibody

Cite This Article: Maniram Kumhar, Chetan Kumar A, and Deepa Kulkarni, "Celiac Disease in Association with a Congenital Heart Disease.” International Journal of Celiac Disease 1, no. 1 (2013): 14-16. doi: 10.12691/ijcd-1-1-6.

\section{Introduction}

Celiac disease (CD) is known to have a varied spectrum of clinical presentations. They may also be associated with multiple diseases involving different systems in the body. We hereby report a rare association of $C D$ with a congenital heart disease - Atrial septal defect (ASD).

\section{Case report}

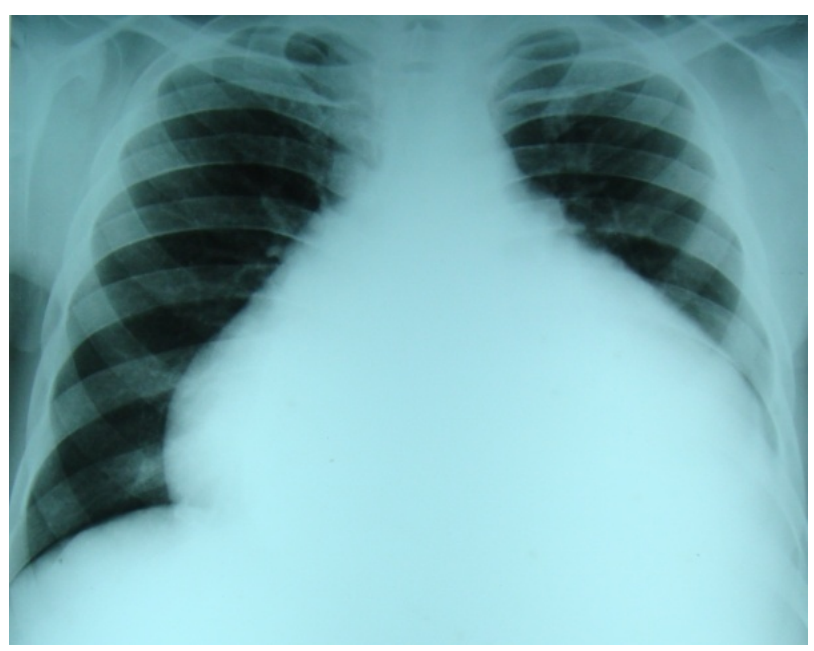

Figure 1. Chest x-ray showing cardiomegaly suggestive of pericardial effusion
A 14 year old female patient presented to our outpatient department with a history of progressive shortness of breath since last couple of years aggravated over the last month. A detailed history revealed multiple hospital admissions during childhood. Her physical and mental developmental milestones were delayed when compared to her siblings. Examination revealed malnourishment and growth impairment. Her height was $128 \mathrm{~cm}$ and weight was $24 \mathrm{kgs}$. She had tachycardia and tachypnea and her blood pressure showed a wide pulse pressure. Pallor and grade 1 clubbing was present on general physical examination. Cardiovascular examination revealed a ejection systolic murmur best heard over the left $2^{\text {nd }}$ and $3^{\text {rd }}$ intercostal space in the parasternal area with a fixed split S2. Gallop rhythm was present with muffled heart sounds. Auscultation of the lung bases revealed crepitations bilaterally. Blood investigations revealed severe anemia (Hemoglobin - 2.4 gm\%) of microcytic hypochromic type. Renal and liver function tests were normal. Chest X-Ray showed massive cardiomegaly and "leather bag" appearance suggestive of pericardial effusion (Figure 1). The left cardiophrenic angle was blunted suggestive of pleural effusion.ECG showed sinus tachycardia with low voltage complexes. Echocardiography (Figure 2) showed severe pericardial effusion without evidence of cardiac tamponade along with ostium secondum type of ASD. CD was considered in view of her malnourished state which was subsequently proved by a grossly elevated anti-transglutaminase antibody-IgA $(>200 \mathrm{U} / \mathrm{ml})$ along with duodenal biopsy microscopy showed marked inflammation and villous 
atrophy suggestive of CD (Figure 3). The patient was put on a gluten free diet. Her cardiac failure secondary to severe anemia was corrected with blood transfusions and diuretics. She was advised routine follow up for monitoring of catch up growth.

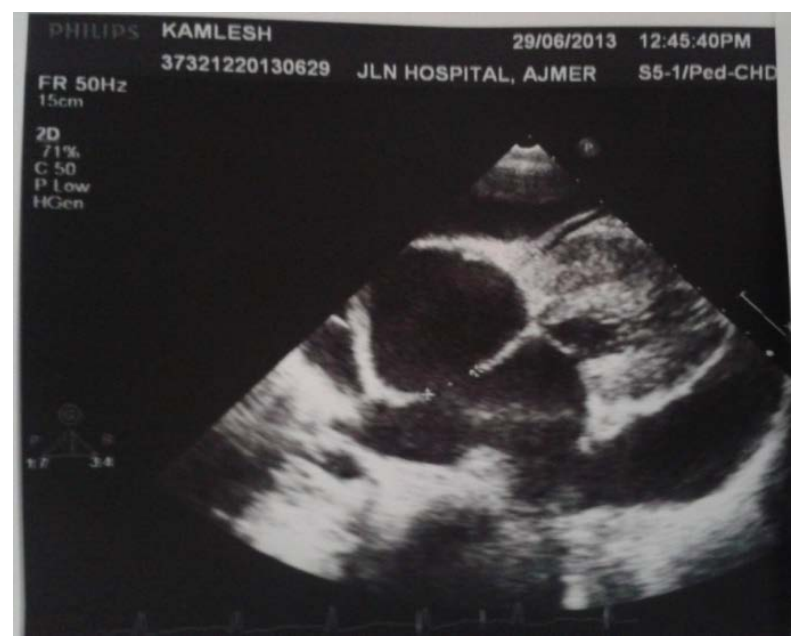

Figure 2. Echocardiography indicating pericardial effusion and ASD

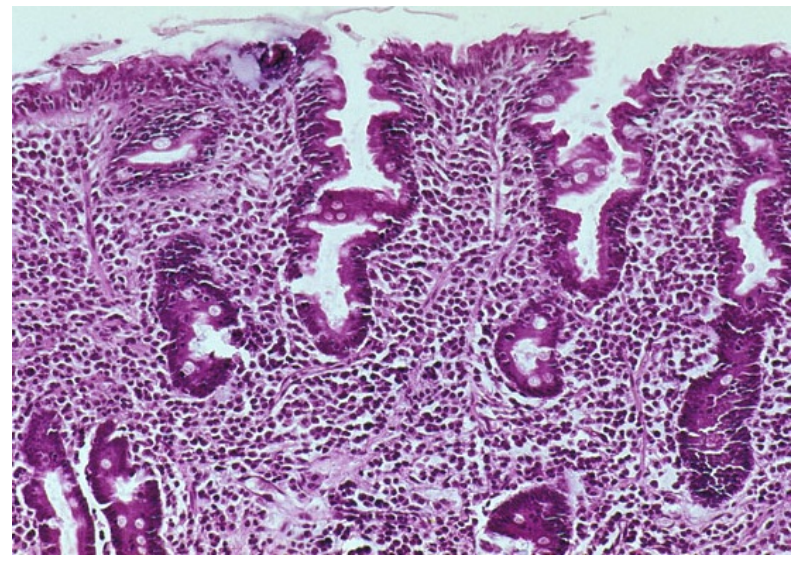

Figure 3. Histopathological study of duodenal biopsy showing marked inflammation and villous atrophy

\section{Discussion}

$\mathrm{CD}$ is defined as an immune mediated disorder caused by the ingestion of gluten and related proteins, occurring in genetically predisposed individuals, and characterized by a variable combination of elevated titers of celiacspecific autoantibodies, an inflammatory enteropathy with variable degrees of severity, and a wide range of gastrointestinal and/or systemic complaints [1].

Atypical $C D$ is fully expressed gluten-sensitive enteropathy manifest only by extraintestinal symptoms and signs including short stature, anemia, osteoporosis, and infertility. Silent $C D$ is fully expressed glutensensitive enteropathy usually found after serologic screening in asymptomatic patients. The atypical and silent variants are more common than classic or typical $\mathrm{CD}$, which is fully expressed gluten-sensitive enteropathy found in association with the classic gastrointestinal symptoms of malabsorption. Serologic testing has demonstrated that silent CD, characterized by positive serology and villus atrophy with few or no symptoms, is approximately seven times more common than symptomatic $\mathrm{CD}$ [2]. Although $\mathrm{CD}$ is rare in the predominantly rice-eating area of southern India, it is prevalent in the Bengal and Punjab provinces of northwest India, where wheat rather than rice has, for many generations, has been a staple of the diet. The interaction of the water-insoluble protein moiety (gluten) of certain cereal grains with the mucosa of the small intestine in susceptible persons is central to the pathogenesis of CD. Family studies demonstrate that the first degree relatives of CD patients have a higher prevalence of the disease. In addition, a strong genetic component is suggested by the concordance rates of $75-80 \%$ in monozygotic twins and $10 \%$ in dizygotic twins [3].

The HLA class II molecule DQ2 is present in more than $90 \%$ of persons with CD compared with approximately $35 \%$ of the general white population. DQ2 is a heterodimer composed of either $\alpha 1 * 0501$ or (less commonly) $\alpha 1 * 0201$ together with $\beta 1 * 02$. The DQ $\alpha 1 * 0301, \beta 1 * 0302$ heterodimer, known as HLA-DQ8, is found in almost all of the remaining patients with CD. There is substantial evidence implicating both humoraland cell-mediated immune responses to gliadin and related prolamins in the pathogenesis of CD. There is a two- to six-fold increase in the numbers of immunoglobulinproducing $\mathrm{B}$ cells in the lamina propria of the small intestine in untreated CD patients [4]. The autoimmune etiopathogenesis of CD is responsible for its multisystem involvement. Common associations of $\mathrm{CD}$ being dermatitis herpitiformis, diabetes mellitus type 1, inflammatory bowel disease, etc. Multiple case reports and studies have been presented to show the association of CD with cardiovascular system. A study conducted by Menezes TM, Motta ME et al on 56 patients between 1nd 18 years in Recife, PE, Brazil showed the association of CD with dilated cardiomyopathy/ mocarditis [5]. A study conducted by Lionetti $\mathrm{E}$ et al in, University of Catania Bari, Italy to assess the prevalence of early cardiac involvement in children with $\mathrm{CD}$, and the impact of a gluten free diet (GFD). Their study done showed Mild cardiac involvement in $13 \mathrm{CD}$ (out of 60) children and in one control $(21.7 \%$ vs. $2.2 \%$; $\mathrm{p}=0.003)$, and was secondary to regurgitation of mitral valve, aortic valve, pulmonary and tricuspid valve, or to impaired ejection fraction. CD children as compared to controls had significantly lower contractility indices, and higher left ventricular dimensions[6]. A similar study conducted by Polat TB, Urganci $\mathrm{N}$ et al in Istanbul, Turkey showed systolic dysfunction of the left ventricle in children with CD [7].

Another study conducted by Emilsson L et al in Arvika, Sweden concluded that patients with CD are at an increased risk of atrial fibrillation [8]. There are many such articles showing various cardiac association of CD, but, there are hardly any cases reported where in CD disease is associated with a congenital heart disease (ASD in our case). Apart from its association with congenital heart disease, pericardial effusion is another rare cardiac manifestation which though may be attributed to severe anemia cannot be overlooked.

\section{Conclusion}

This case was reported to bring in to light the various cardiac manifestations of $\mathrm{CD}$ particularly the rare 
association of a congenital heart disease (ASD in this case) with CD.

\section{References}

[1] Ludvigsson JF, Leffler DA, Bai JC et al (2013). The Oslo definitions for coeliac disease and related terms. Gut 62: 43-52.

[2] Catassi C, Fabiani E, Ratsch IM, et al: The coeliac iceberg in Italy: A multicentre antigliadin antibodies screening for coeliac disease in school-age subjects. Acta Paediatr Suppl 1996; 412:29.

[3] E Rivera,A Assiri, S Guandalini, Celiac disease : review article, Oral Diseases (2013) 19, 635-641.

[4] Wright NA, Watson AJ, Morley AR, et al: Cell production rate in mucosa of untreated coeliac disease. Gut 1972; 13:846.
[5] Menezes TM, Motta ME et al Celiac disease prevalence in children and adolescents with myocarditis and dilated cardiomiopathy J. Pediatr. (Rio J.) vol.88 no.5 Porto Alegre Sept./Oct. 2012.

[6] Lionetti E, Catassi C, Francavilla R, et al Subclinic cardiac involvement in paediatric patients with celiac disease: a novel sign for a case finding approach J Biol Regul Homeost Agents. 2012 Jan-Mar;26(1 Suppl):S63-8.

[7] Polat TB, Urganci $\mathrm{N}$ et al Cardiac functions in children with coeliac disease during follow-up: insights from tissue Doppler imaging. Dig Liver Dis. 2008 Mar;40(3):182-7.

[8] Emilsson L, Smith JG et al Increased risk of atrial fibrillation in patients with coeliac disease: a nationwide cohort study. Eur Heart J. 2011 Oct; 32(19):2430-7. 